Supplement of The Cryosphere, 15, 1215-1236, 2021

https://doi.org/10.5194/tc-15-1215-2021-supplement

(C) Author(s) 2021. This work is distributed under

the Creative Commons Attribution 4.0 License.

(c) (1)

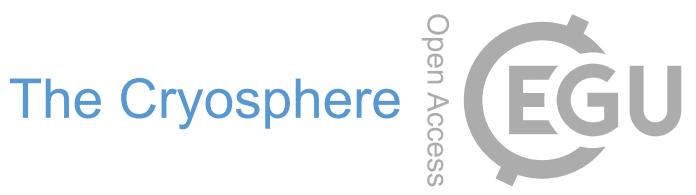

Supplement of

\title{
Diverging future surface mass balance between the Antarctic ice shelves and grounded ice sheet
}

\section{Christoph Kittel et al.}

Correspondence to: Christoph Kittel (ckittel@uliege.be)

The copyright of individual parts of the supplement might differ from the CC BY 4.0 License. 


\section{S1 Evaluation of MAR forced by ERA5}

Although an exhaustive assessment of MAR is not the main purpose of this study, we present here a short evaluation of MARv3.11 forced by ERA5. The SMB and near-surface climate modelled by MAR have already been evaluated over Antarctica (Kittel et al., 2018; Agosta et al., 2019; Mottram et al., 2020), but with previous versions of the model and with the ERA-Interim reanalysis as forcings. We therefore compare MARv3.11 using the same methods to the same 184 AWS and 983 averaged-SMB observations used in Mottram et al. (2020) to evaluate the new version of MAR and its results forced by the new ERA5 reanalysis, which replaced ERA-Interim, hitherto considered to be the best reanalysis in Antarctica (Agosta et al., 2015). We refer to Mottram et al. (2020) for a more detailed descriptions of the observation dataset and the method) MARv3.10 forced by ERA-Interim (as used in Mottram et al. (2020)) is presented for comparison. Since the two versions of MAR are not forced by the same reanalyses, the purpose of this section is to demonstrate that the latest version of MAR forced by ERA5 performs equally well (not to discuss differences between the two versions in detail) and can be considered as a reference to evaluate our simulations forced by ESMs over the historical period.

\section{S1.1 Comparison against near-surface climate observations}

Using either MARv3.11 (forced by ERA5; MAR(ERA5)) or MARv3.10 (forced by ERA-Interim) yields very equivalent statistical performance when evaluated against near-surface meteorological observations over 1987 - 2015 (Tab. S1). MAR(ERA5) displays a non significantly-improved correlation with surface pressure as a result of a stronger upper nudging and/or the more sophisticated (i.e, more recent) forcing. The representation of the near-surface wind speed is improved while MAR still underestimates the mean wind speed. The model tends to overestimate low wind-speed values but underestimates high wind-speed values resulting in this negative bias. Regarding the near-surface temperature, the mean annual (summer) positive bias is increased by $+1.01^{\circ} \mathrm{C}\left(+0.52^{\circ} \mathrm{C}\right)$. This bias reflects a difference between low and high temperatures (and is therefore linked to elevation and seasons). MAR overestimates low temperatures (especially on the plateau or in winter) while it slightly underestimates the high temperatures (close to $0^{\circ} \mathrm{C}$ ). This likely results from a bias in the radiative scheme itself resulting from the version of the radiative scheme (from the ERA-40 reanalysis) and/or the low-sophisticated one-moment cloud scheme in MAR.

\section{S1.2 Comparison against SMB observations}

Both versions of MAR also have equivalent statistics for the SMB comparison (Fig. S11). The few slight improvements in one indicator are compensated for by alterations in other statistics, meaning that MAR(ERA5) is close to MARv3.10, the latter being assessed as one of the best models to represent the Antarctic SMB (Mottram et al., 2020). In general, MAR can reproduce the strong coast-to-plateau SMB gradient with high SMB values over low-elevations margins and weak accumulation over the high plateau. 
Table S1. Mean bias, RMSE, centered RMSE (RMSEc), and correlation between daily observations and MAR(ERA5) and MARv3.10. Annual and summer statistics are given for surface pressure, near-surface temperature and wind speed. The statistic indicators suggest that both version have very similar results when compared to AWS observations.

\begin{tabular}{|c|c|c|c|c|c|c|c|c|c|}
\hline & & \multicolumn{4}{|c|}{ Annual } & \multicolumn{4}{|c|}{ Summer } \\
\hline & & Mean bias & RMSE & RMSEc & Correlation & Mean bias & RMSE & RMSEc & Correlation \\
\hline Surface & MAR(ERA5) & -4.22 & 10.17 & 2.44 & 0.97 & -5.51 & 10.34 & 2.03 & 0.96 \\
\hline pressure $(\mathrm{hPa})$ & MAR3.10 & -4.05 & 7.42 & 2.80 & 0.96 & -6.13 & 8.46 & 2.28 & 0.96 \\
\hline \multicolumn{2}{|c|}{ Mean obs 1987-2015 } & \multicolumn{4}{|c|}{955.46} & \multicolumn{4}{|c|}{1.44} \\
\hline \multicolumn{2}{|c|}{ Standard obs 1987-2015 } & \multicolumn{4}{|c|}{10.20} & \multicolumn{4}{|c|}{8.02} \\
\hline Near-surface & MAR(ERA5) & 1.33 & 4.39 & 3.39 & 0.94 & 0.69 & 2.96 & 2.32 & 0.86 \\
\hline Temperature $\left({ }^{\circ} \mathrm{C}\right)$ & MARv3.10 & 0.32 & 4.21 & 3.62 & 0.94 & 0.17 & 2.72 & 2.41 & 0.85 \\
\hline \multicolumn{2}{|c|}{ Mean obs 1987-2015 } & \multicolumn{4}{|c|}{-19.91} & \multicolumn{4}{|c|}{-8.11} \\
\hline \multicolumn{2}{|c|}{ Standard obs 1987-2015 } & \multicolumn{4}{|c|}{10.21} & \multicolumn{4}{|c|}{4.43} \\
\hline Near-surface & MAR(ERA5) & -0.53 & 2.72 & 2.24 & 0.74 & -0.70 & 2.28 & 1.86 & 0.70 \\
\hline wind $(\mathrm{m} / \mathrm{s})$ & MARv3.10 & -0.59 & 2.85 & 2.40 & 0.71 & -0.77 & 2.33 & 1.96 & 0.67 \\
\hline \multicolumn{2}{|c|}{ Mean obs 1987-2015 } & \multicolumn{4}{|c|}{6.02} & \multicolumn{4}{|c|}{3.44} \\
\hline \multicolumn{2}{|c|}{ Standard obs 1987-2015 } & \multicolumn{4}{|c|}{4.93} & \multicolumn{4}{|c|}{2.67} \\
\hline
\end{tabular}

\section{S1.3 Comparison against melt estimates}

The amount of melt water is low over the present climate, but is expected to increase in the future and may therefore become a major surface process. This is why we also compared the melt simulated by MAR(ERA5) to the annual AWS-forced estimates from Jakobs et al. (2020). MAR melt values were computed using a four-nearest inverse-distance-weighted method for all the AWS whose the elevation difference with MAR does not exceed 250m. Figure S2 shows that MAR(ERA5) can correctly reproduce the annual meltwater estimates. MAR underestimates the relatively-weak melt at AWS14 (located over Larsen C North). The $35 \mathrm{~km}$ resolution of our simulations is probably still too coarse to correctly reproduce the Foehn winds inducing surface melting (Datta et al., 2019). 

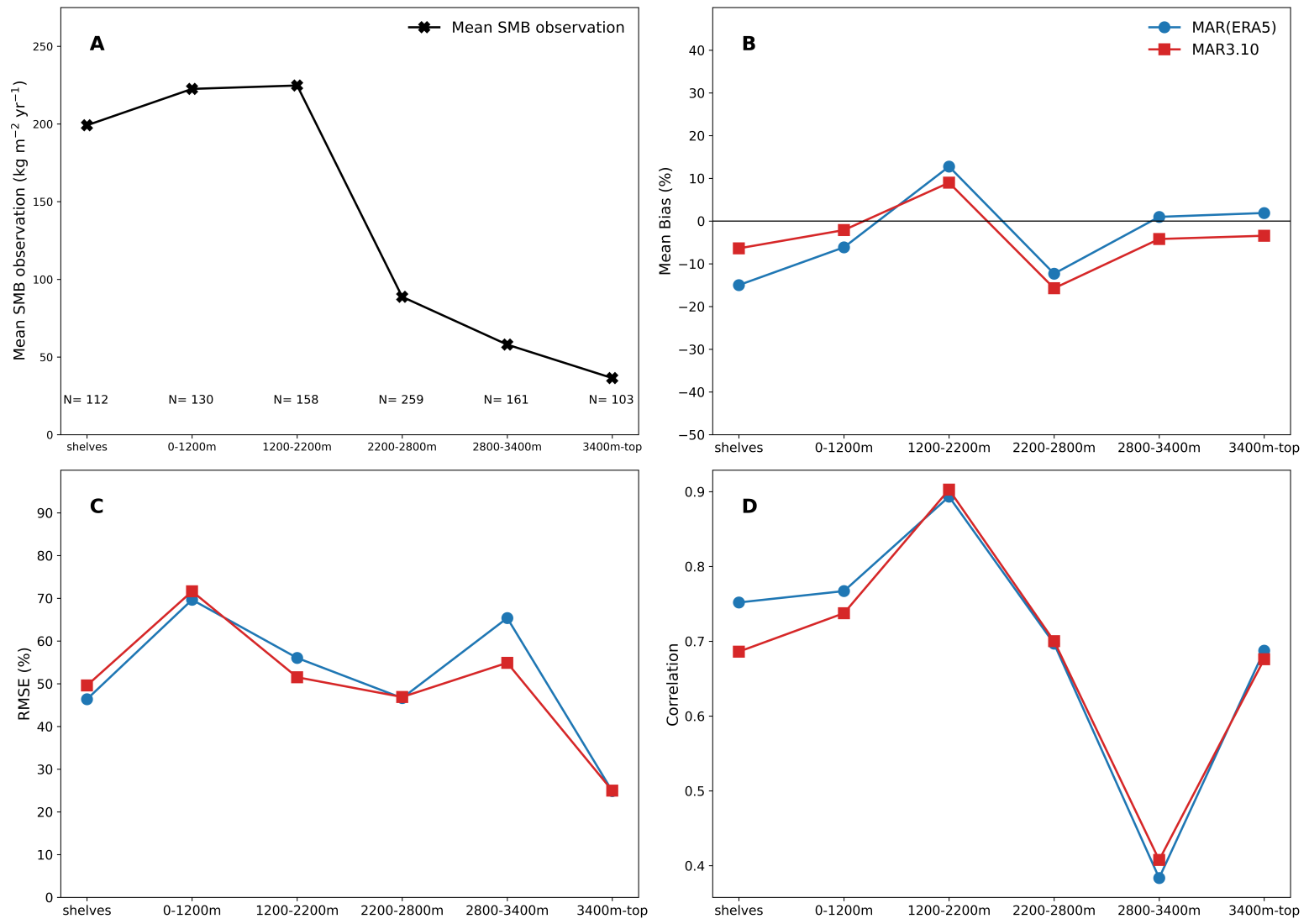

Figure S1. A. Mean SMB observation value $\left(\mathrm{kg} \mathrm{m}^{-2} \mathrm{yr}^{-1}\right)$ for each elevation class. Number of comparison pairs per class is also indicated. MAR3.10 and MAR(ERA5) B. mean biases (\% of the mean class-averaged SMB), C. RMSE (\% of the mean class-averaged SMB), and D. correlation for each elevation class. The statistic indicators suggest that both version yield very similar results when compared to SMB observations. 


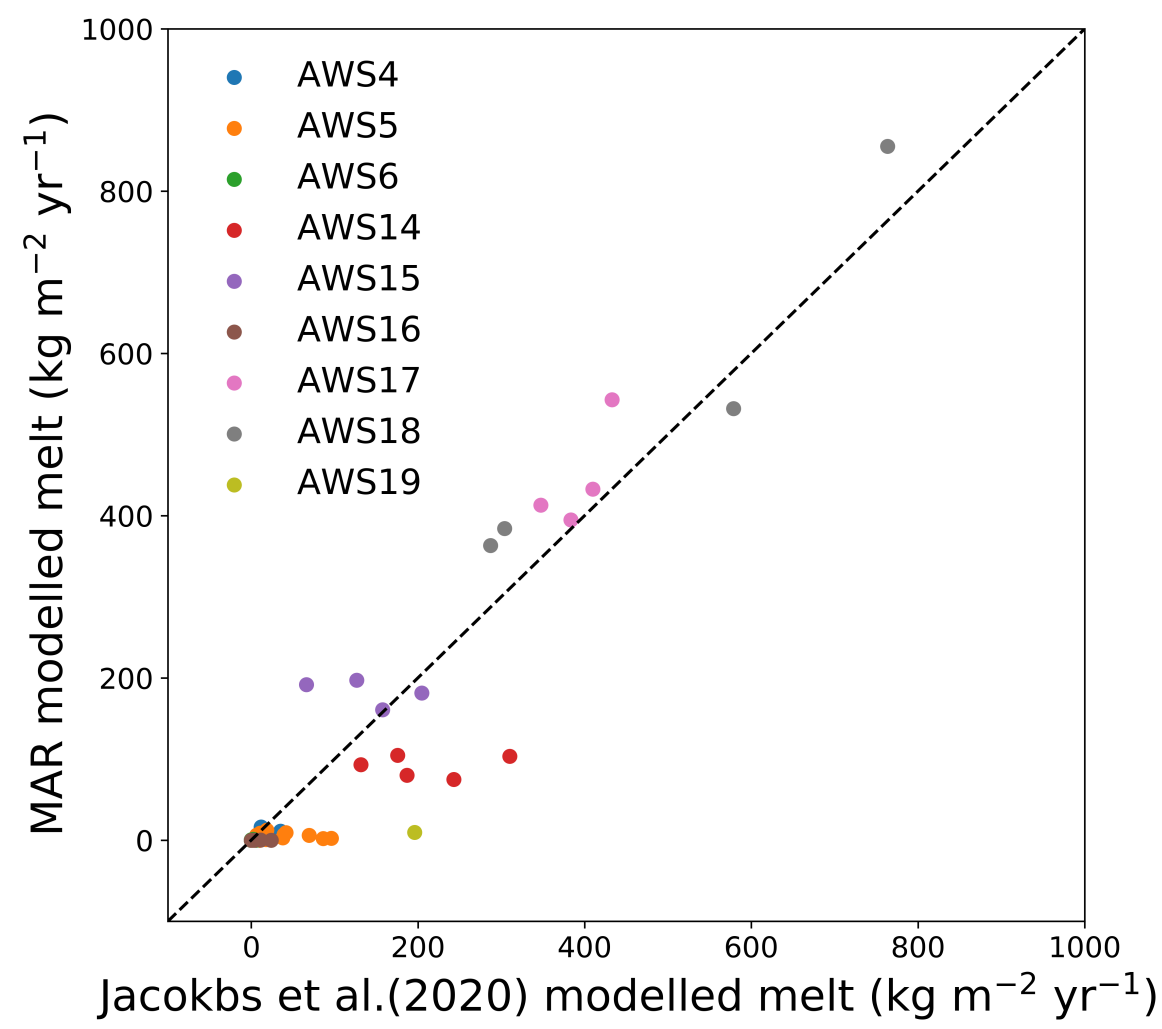

Figure S2. Comparison between MAR annual melt $\left(\mathrm{kg} \mathrm{m}^{-2} \mathrm{yr}^{-1}\right)$ and AWS-forced melt estimates modelled by Jakobs et al. (2020) $\left(\mathrm{kg} \mathrm{m}^{-2} \mathrm{yr}^{-1}\right)$ at 9 AWS locations. 
A. TT MAR(ACCESS1 3) - MAR(ERA5)

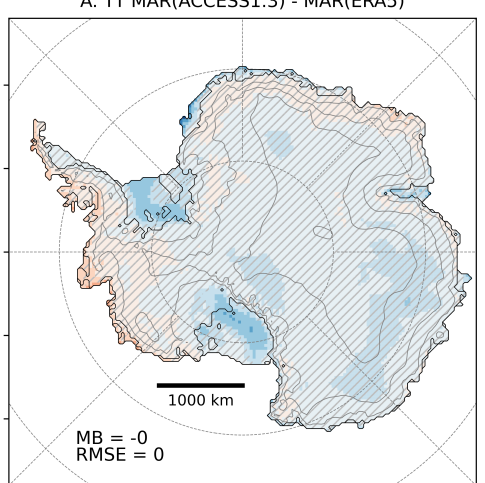

C. TT MAR(CNRM-CM6-1) - MAR(ERA5)

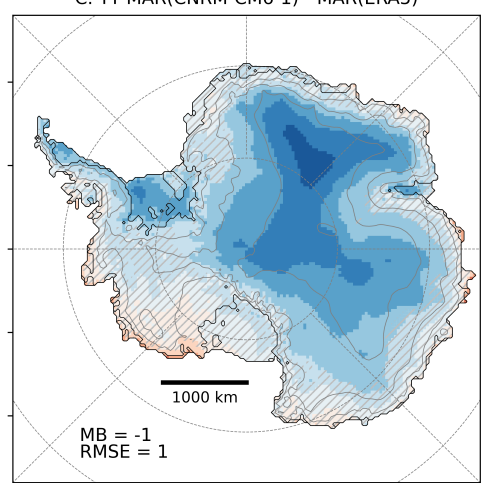

B. TT MAR(NORESM1-M) - MAR(ERA5)

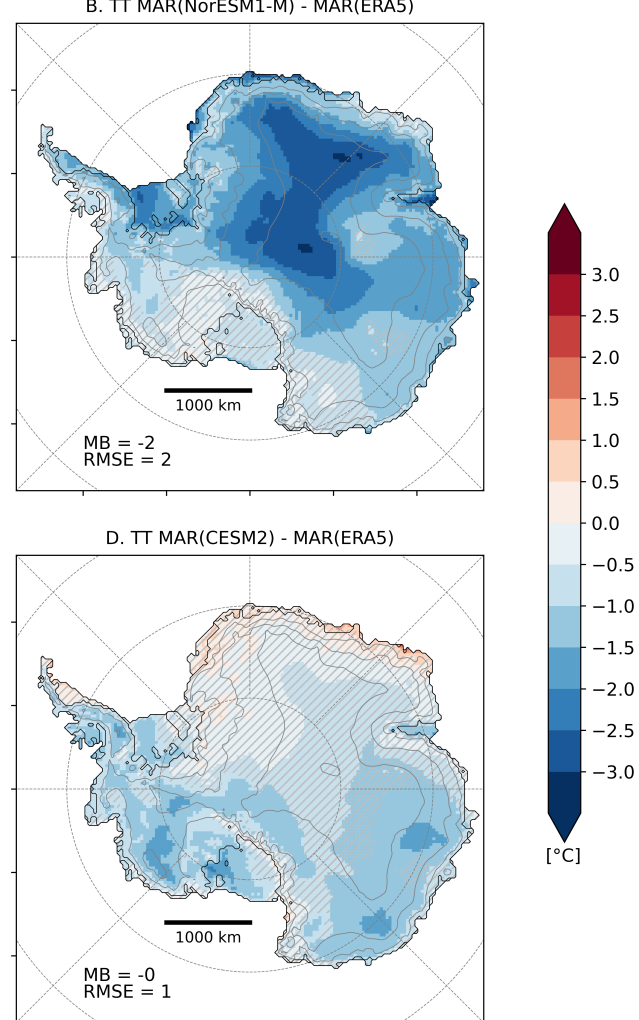

Figure S3. Comparison between the mean summer near-surface temperature simulated by MAR forced by ACCESS1.3 (A), NorESM1-M (B), CNRM-CM6-1 (C), CESM2 (D) and the mean summer near-surface temperature simulated by MAR(ERA5) $\left({ }^{\circ} \mathrm{C}\right)$ over 1981-2010. Locations where anomalies are smaller than the (natural) interannual variability of the present climate (interannual standard deviation) are hatched. Spatial Root Mean Square Error (RMSE) and mean bias (MB) of the experiment compared to MAR(ERA5) are also indicated. 

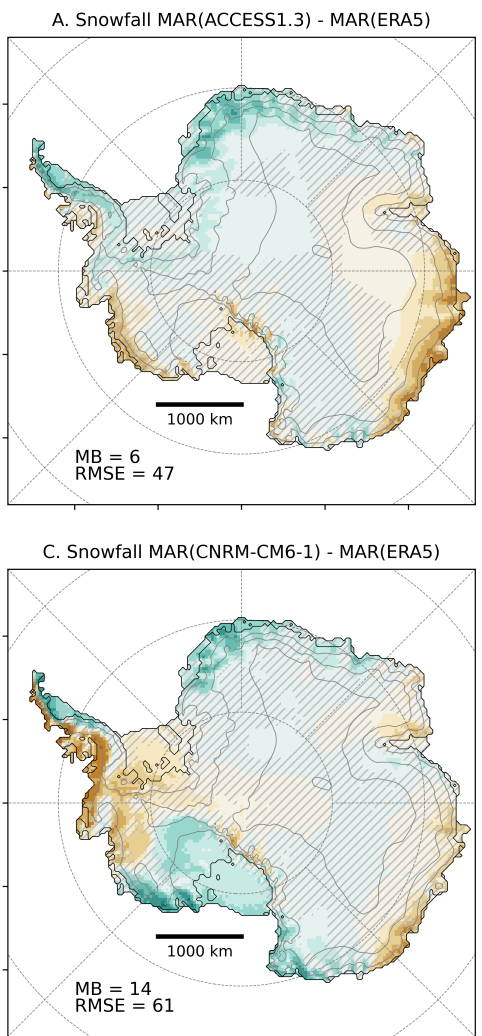

B. Snowfall MAR(NorESM1-M) - MAR(ERA5)

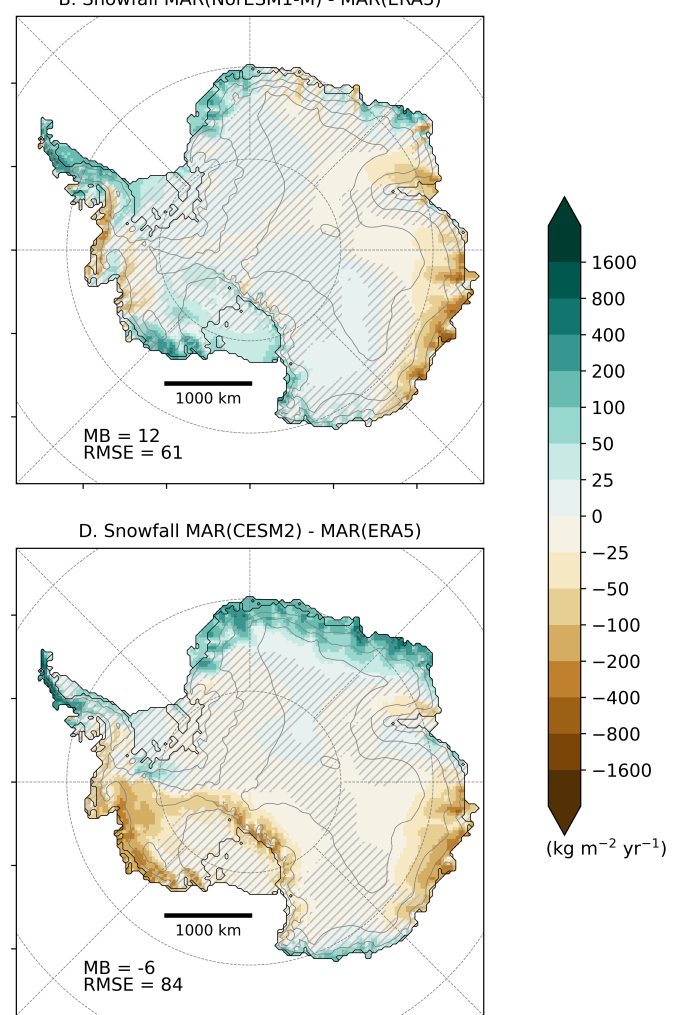

Figure S4. Comparison between the mean annual SF simulated by MAR forced by ACCESS1.3 (A), NorESM1-M (B), CNRM-CM6-1 (C), CESM2 (D) and the mean annual SF simulated by MAR(ERA5) $\left(\mathrm{kg} \mathrm{m}^{-2} \mathrm{yr}^{-1}\right)$ over 1981-2010. Locations where anomalies are smaller than the (natural) interannual variability of the present climate (interannual standard deviation) are hatched. Spatial Root Mean Square Error (RMSE) and mean bias (MB) of the experiment compared to MAR(ERA5) are also indicated. 
Table S2. Top: annual mean and standard deviation of SMB, snowfall, rainfall, net sublimation (sublimation - deposition), runoff and meltwater $\left(\mathrm{Gt} \mathrm{yr}^{-1}\right)$ integrated over the whole AIS for MAR(ERA5) over 1981-2010. Bottom: Difference of annual mean integrated SMB, snowfall, rainfall, net sublimation (sublimation - deposition), runoff and meltwater ( $\mathrm{Gt}^{-1}{ }^{-1}$ ) between each MAR(ESM) experiment and MAR(ERA5) over 1981-2010

\begin{tabular}{|c|c|c|c|c|c|c|}
\hline $\operatorname{Mean}\left(\mathrm{Gt} \mathrm{yr}^{-1}\right)$ & SMB & SF & $\mathrm{RF}$ & SU & RU & ME \\
\hline MAR(ERA5) & $2686 \pm 116$ & $2894 \pm 112$ & $19 \pm 3$ & $173 \pm 11$ & $54 \pm 14$ & $174 \pm 38$ \\
\hline Anomaly $\left(\mathrm{Gt} \mathrm{yr}^{-1}\right)$ & SMB & $\mathrm{SF}$ & $\mathrm{RF}$ & SU & RU & $\mathrm{ME}$ \\
\hline MAR(ACCESS1.3) & -3 & -22 & 11 & -8 & 0 & 0 \\
\hline MAR(NorESM1-M) & 92 & 38 & 1 & -22 & -31 & -72 \\
\hline MAR(CNRM-CM6-1) & 60 & 8 & 11 & -10 & -31 & -48 \\
\hline MAR(CESM2) & -26 & -58 & -5 & -4 & -33 & -71 \\
\hline
\end{tabular}




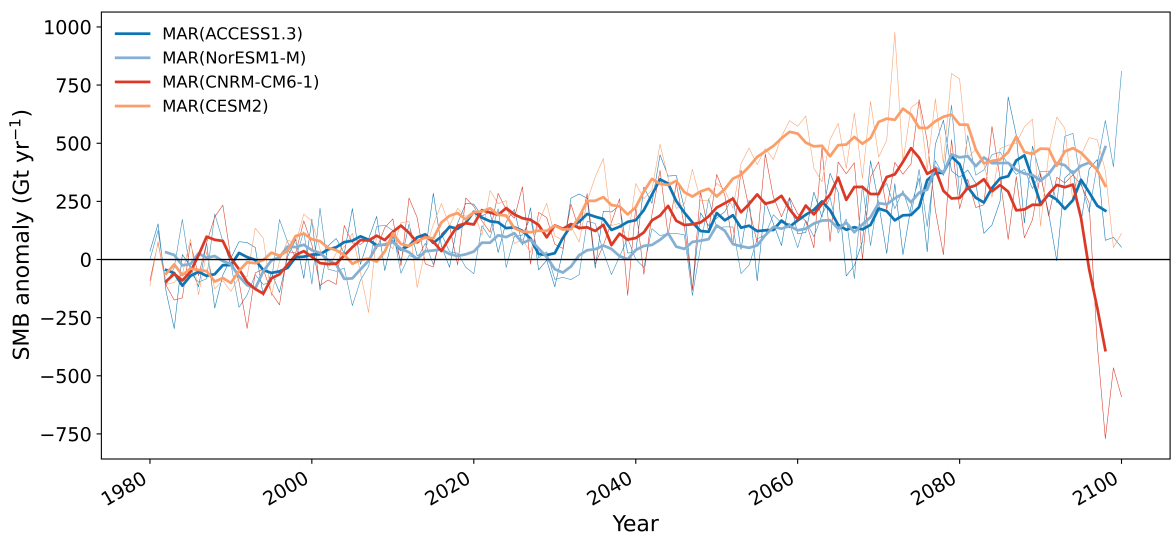

Figure S5. Time series of the integrated annual Antarctic (ice shelves included) SMB anomaly (Gt $\mathrm{yr}^{-1}$ ) from 1980 to 2100 in the highemission scenarios (RCP8.5 and ssp585) simulated by MAR forced by ACCESS1-3 (blue), NorESM1-M (light blue), CNRM-CM6 (red), and CESM2 (orange) compared to the 1981-2010 reference period. A running average of 5 years was applied to the original values, while the original annual anomalies are shown as thinner lines in the background.

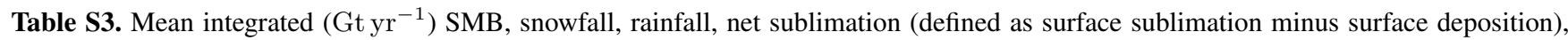
runoff and melt for the grounded ice sheet and the ice shelves over 2071-2100 from RCP8.5 and ssp585 simulations..

\begin{tabular}{|c|c|c|c|c|c|c|}
\hline Mean $\left(\mathrm{Gt} \mathrm{yr}^{-1}\right)$ over $2071-2100$ & SMB & Snowfall & Rainfall & Net Sublimation & Runoff & Melt \\
\hline \multicolumn{7}{|l|}{ Grounded ice $\left(11.94 \times 10^{6} \mathrm{~km}^{2}\right)$} \\
\hline MAR(ACCESS1.3) & 2596 & 2829 & 50 & 117 & 166 & 330 \\
\hline MAR(NorESM1-M) & 2573 & 2688 & 27 & 103 & 39 & 108 \\
\hline MAR(CNRM-CM6-1) & 2829 & 3084 & 98 & 87 & 266 & 527 \\
\hline MAR(CESM2) & 2909 & 3148 & 83 & 97 & 225 & 419 \\
\hline \multicolumn{7}{|l|}{ Ice shelves $\left(1.77\right.$ x $\left.10^{6} \mathrm{~km}^{2}\right)$} \\
\hline MAR(ACCESS1.3) & 372 & 637 & 57 & 55 & 267 & 536 \\
\hline MAR(NorESM1-M) & 584 & 694 & 29 & 55 & 84 & 253 \\
\hline MAR(CNRM-CM6-1) & 180 & 679 & 124 & 49 & 574 & 869 \\
\hline MAR(CESM2) & 263 & 706 & 97 & 48 & 492 & 781 \\
\hline
\end{tabular}




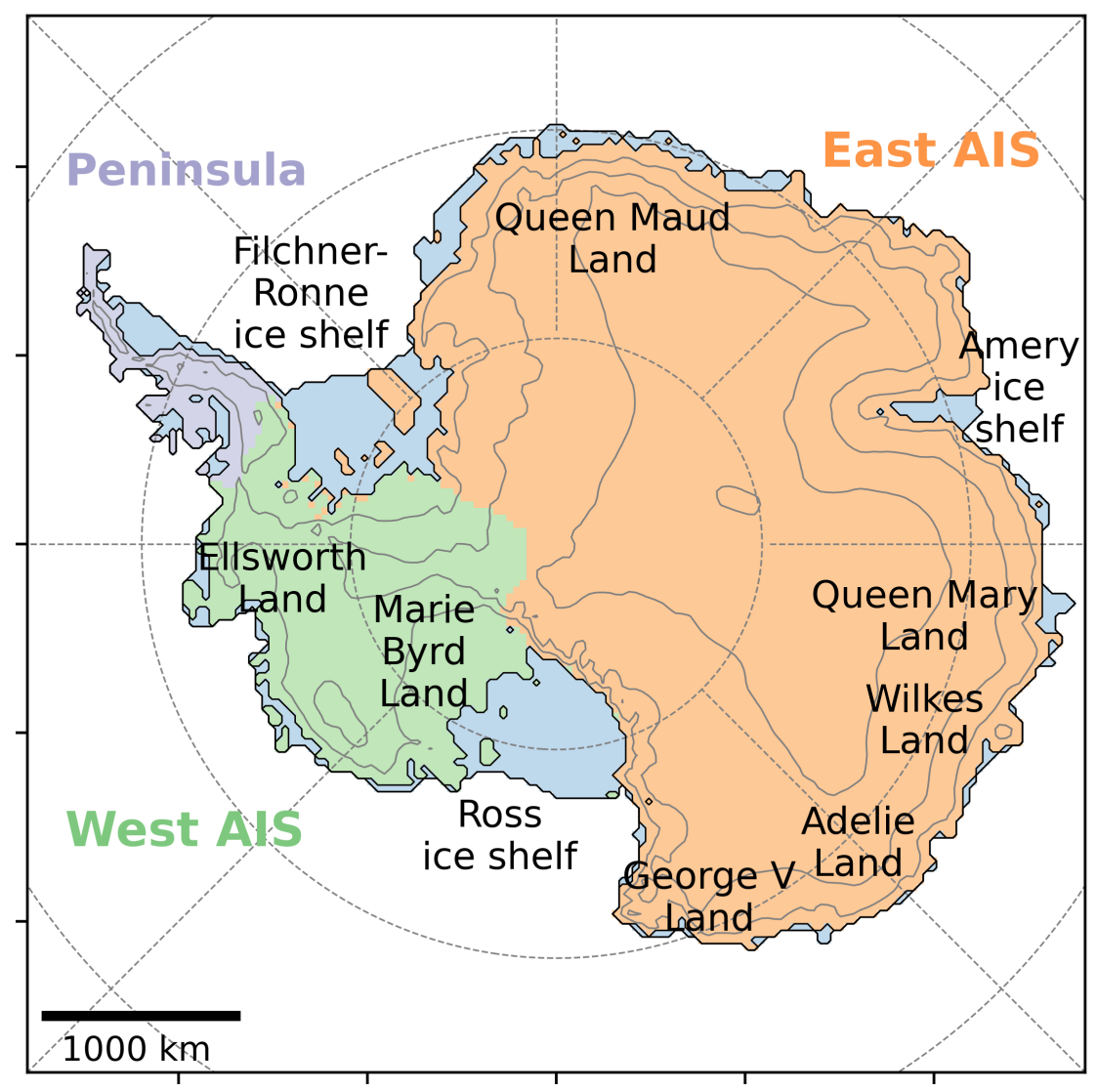

Figure S6. The Antarctic regions and sub-regions discussed in the manuscript with elevations contours every $1000 \mathrm{~m}$. The ice shelves are represented in light blue.

Table S4. The 30-year periods corresponding to an increase in Antarctic $\left(90^{\circ} \mathrm{S}-60^{\circ} \mathrm{S}\right)$ near-surface temperature of $\sim+2.5^{\circ} \mathrm{C}$ for the four selected ESMs. Exact near-surface warming is also indicated

\begin{tabular}{lrr}
\hline ESM & 30-year period & Near-surface temperature increase $\left({ }^{\circ} \mathrm{C}\right)$ \\
\hline ACCESS1.3 & $2041-2070$ & 2.45 \\
NorESM1-M & $2071-2100$ & 2.54 \\
CNRM-CM6-1 & $2031-2060$ & 2.44 \\
CESM2 & $2031-2060$ & 2.44 \\
\hline
\end{tabular}


A. SP MAR(ACCESS1.3) future - present

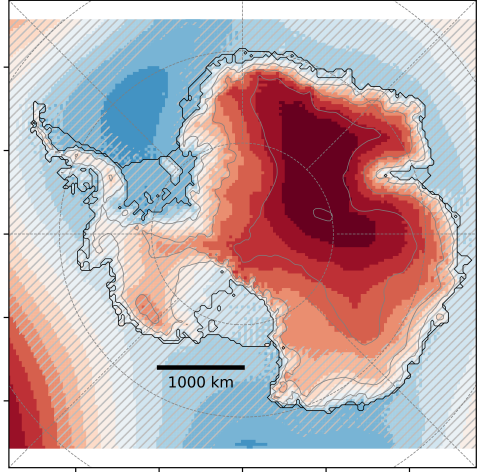

C. SP MAR(CNRM-CM6-1) future - present

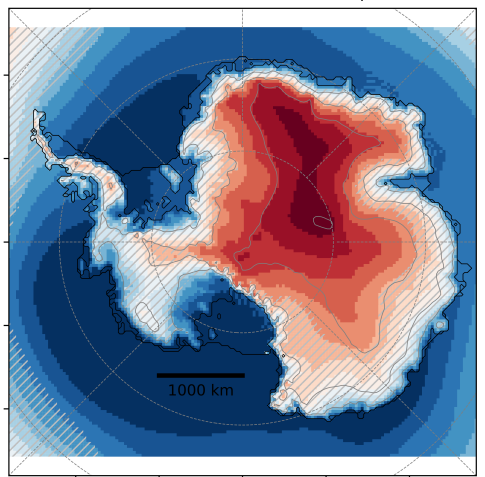

B. SP MAR(NorESM1-M) future - present

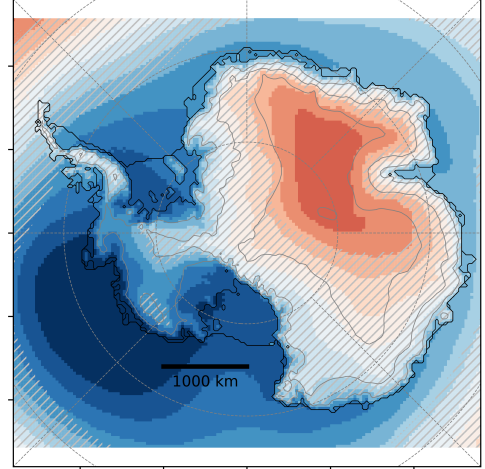

D. SP MAR(CESM2) future - present

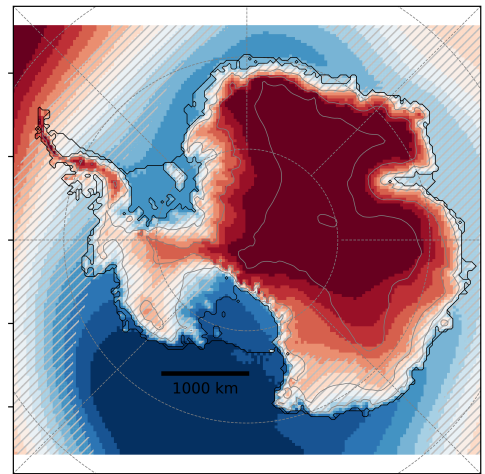

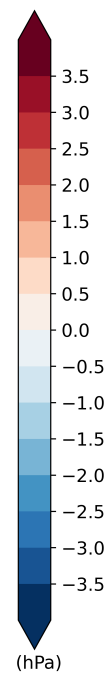

Figure S7. Surface pressure changes ( $\mathrm{hPa}$ ) between 2071-2100 and 1981-2010 as modelled by MAR forced by ACCESS1-3 (A), NorESM1M (B), CNRM-CM6-1 (C), and CESM2 (D). Locations where changes are smaller than the (natural) interannual variability of the present climate (interannual standard deviation) are hatched. 

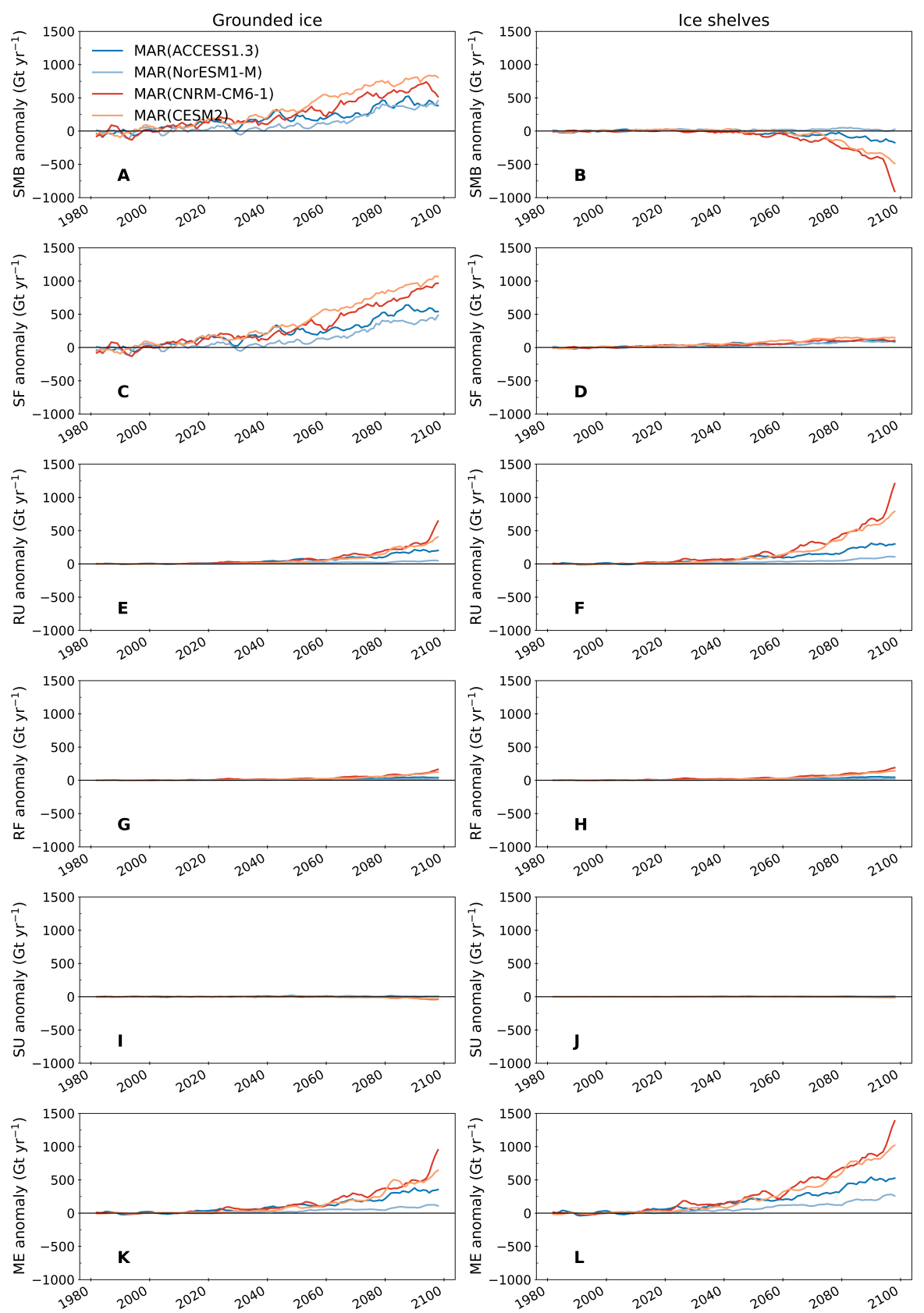

Figure S8. Time series of the integrated annual SMB (A, B), snowfall (C, D), runoff (E, F), rainfall (G, H), sublimation (I, J) and melt (K, L) anomalies $\left(\mathrm{Gt} \mathrm{yr}^{-1}\right.$ ) over the Antarctic grounded ice (A, C, E, G, I, K) and the Antarctic ice shelves (B, D, F, H, J, L) from 1980 to 2100 simulated by MAR forced by ACCESS1-3 (blue), NorESM1-M (light blue), CNRM-CM6 (red), and CESM2 (orange) compared to the 1981-2010 reference period. Sublimation changes are weak and do not contribute to variations in SMB. Melt anomalies follow a similar pattern than runoff anomalies suggesting than a almost all of the melt water is lost for the ice sheet as runoff. 

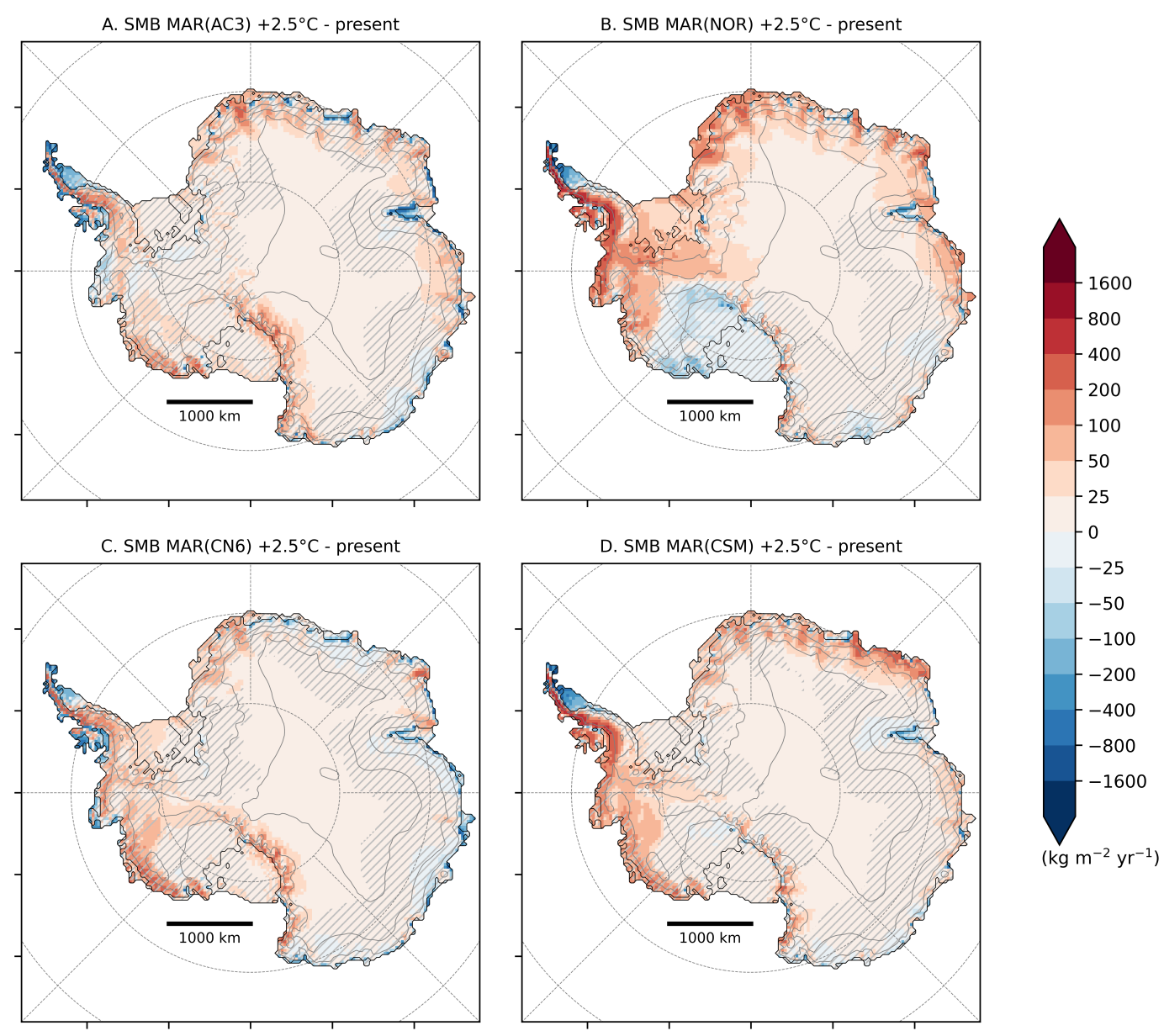

Figure S9. SMB changes $\left(\mathrm{kg} \mathrm{m}^{-2} \mathrm{yr}^{-1}\right)$ between a $+2.5^{\circ} \mathrm{C}$ warmer climate and the historical period by MAR forced by ACCESS1-3 (A), NorESM1-M (B), CNRM-CM6-1 (C), and CESM2 (D). Locations where changes are smaller than the (natural) interannual variability of the present climate (interannual standard deviation) are hatched. 

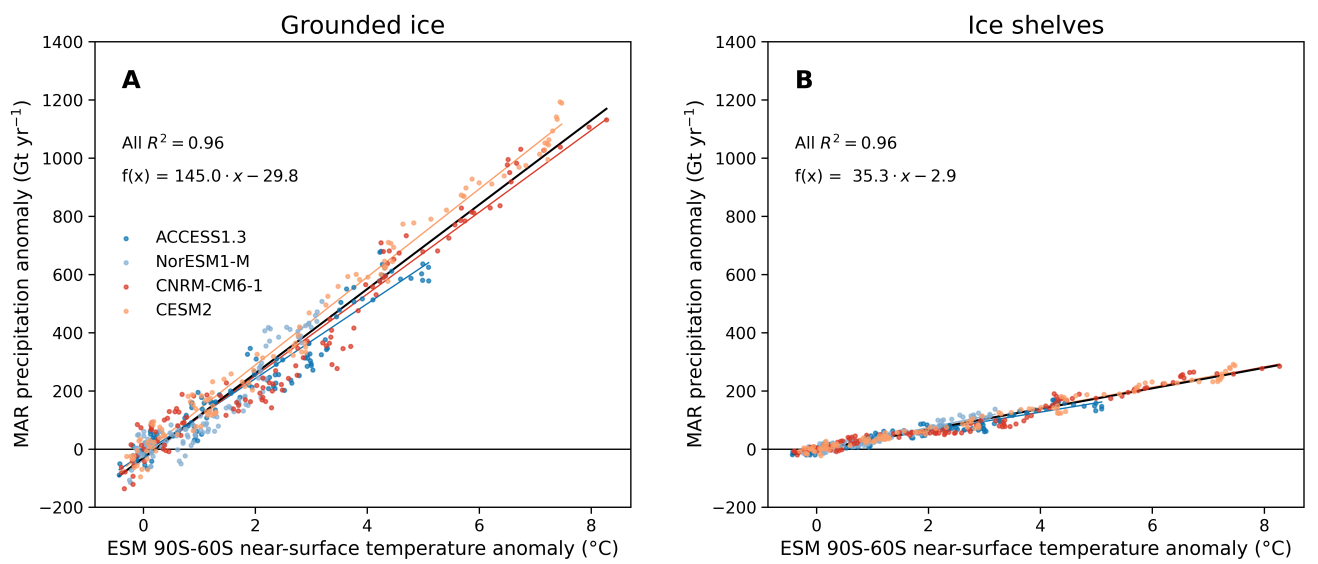

Figure S10. MAR total (snowfall + rainfall) precipitations anomalies $\left(\mathrm{Gt} \mathrm{yr}^{-1}\right)$ over the grounded ice (A) and ice shelves (B) compared to the annual near-surface temperature anomaly from the forcing ESMs between $90^{\circ} \mathrm{S}-60^{\circ} \mathrm{S}\left({ }^{\circ} \mathrm{C}\right)$. The black regression was computed using all the MAR-ESM anomalies while individual regression are also represented (coloured lines). The regression equation and determination coefficient are mentioned for each scatter plot. 
Figure S11 compares the modelled MAR SMB anomalies to the ESM reconstructed SMB anomalies. The reconstruction based on the temperature anomaly accurately reconstructs the modeled SMB over the grounded ice (RMSE $=68 \mathrm{Gt} \mathrm{yr}^{-1}$, i.e lower than the present interannual grounded-SMB variabily in our MAR(ERA5) reference simulations wich is $99 \mathrm{Gt} \mathrm{yr}^{-1}$ ), but is slightly less precise over the ice shelves $\left(\mathrm{RMSE}=38 \mathrm{Gt} \mathrm{yr}^{-1}\right.$, i.e larger than the present interannual ice-shelf SMB variability wich is $22 \mathrm{Gt} \mathrm{yr}^{-1}$ ). This is mainly due to the large decrease in SMB for MAR(CNRM-CM6-1) that is not fully represented by the regression (also valid for the grounded fit). The projected changes with the strongest warming are however much larger than the error of the regression. Moreover, among all CMIP5 and CMIP6 models, CNRM-CM6-1 projects the strongest warming in 2100, thus allowing us to use our regression to reconstruct the SMB for all CMIP5 and CMIP6 models. Note that using a similar method based on the link between individual SMB components (snowfall, rainfall and ablation) and ESM near-surface anomalies also yields a similar reconstruction. This demonstrates that the future response of the surface of both ice shelves and grounded ice can be mainly determined using the temperature warming until the end of the 21 st century.
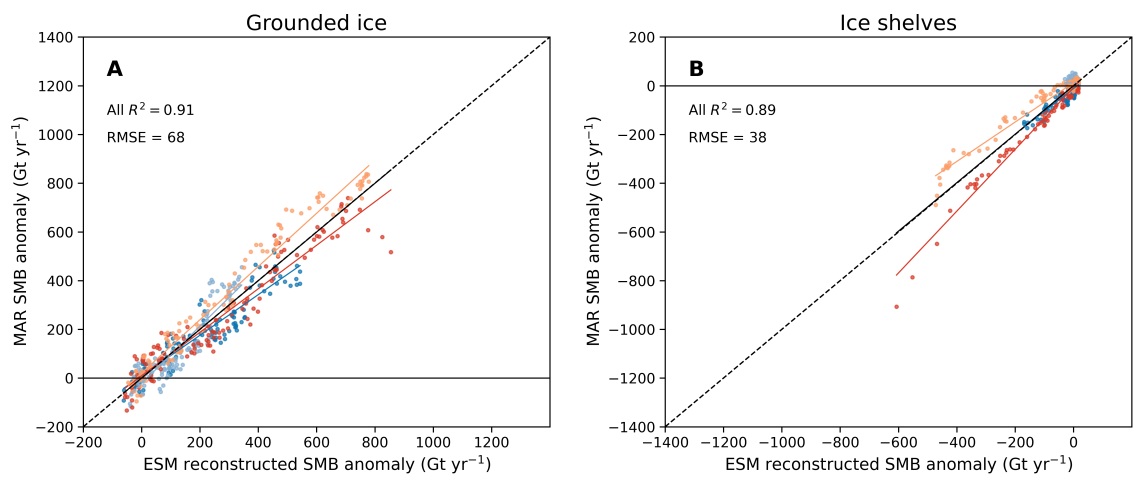

Figure S11. Comparison of the MAR SMB anomaly $\left(\mathrm{Gt} \mathrm{yr}^{-1}\right)$ with the corresponding-ESM reconstructed-SMB anomaly $\left(\mathrm{Gt}^{-1} \mathrm{yr}^{-1}\right)$ based $^{-\mathrm{S}}$ on the regression between SMB and ESM near-surface temperature over the grounded ice (A) and over the ice shelves (B). The evaluation of the regression is done by indicating the Root Mean Square Error (RMSE, Gt yr ${ }^{-1}$ ) and determination coefficient 


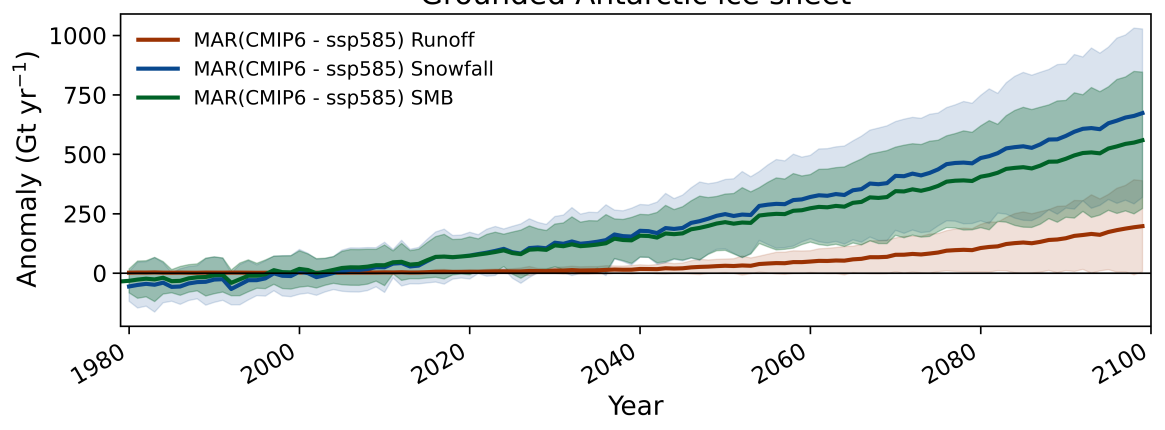

Figure S12. Reconstructed snowfall (blue), runoff (red) and SMB (green) anomaly Gt $\mathrm{yr}^{-1}$ using CMIP6 (ssp585) models over the Antarctic grounded ice. Projections are shown using the multi-model mean (solid lines) and the 5 to $95 \%$ range, corresponding to \pm 1.64 standard deviation, across the distribution of individual models (shading).
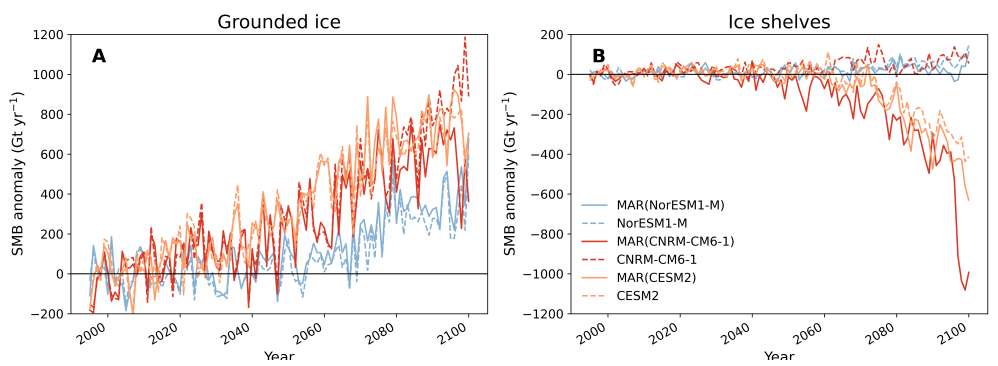

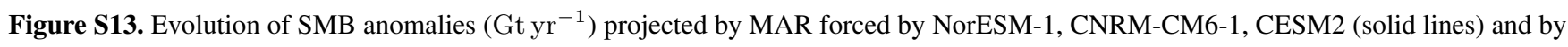
the respective forcing ESMs (dashed lines) over the grounded ice (A) and the ice shelves (B) 


\section{References}

Agosta, C., Fettweis, X., and Datta, R.: Evaluation of the CMIP5 models in the aim of regional modelling of the Antarctic surface mass balance, Cryosphere, 9, 2311-2321, https://doi.org/10.5194/tc-9-2311-2015, 2015.

55 Agosta, C., Amory, C., Kittel, C., Orsi, A., Favier, V., Gallée, H., van den Broeke, M. R., Lenaerts, J., van Wessem, J. M., van de Berg, W. J., et al.: Estimation of the Antarctic surface mass balance using the regional climate model MAR (1979-2015) and identification of dominant processes, Cryosphere, 13, 281-296, 2019.

Datta, R. T., Tedesco, M., Fettweis, X., Agosta, C., Lhermitte, S., Lenaerts, J. T., and Wever, N.: The effect of Foehn-induced surface melt on firn evolution over the northeast Antarctic peninsula, Geophysical Research Letters, 46, 3822-3831, 2019.

60 Jakobs, C. L., Reijmer, C. H., Smeets, C. P., Trusel, L. D., Van De Berg, W. J., Van Den Broeke, M. R., and Van Wessem, J. M.: A benchmark dataset of in situ Antarctic surface melt rates and energy balance, Journal of Glaciology, 66, 291-302, 2020.

Kittel, C., Amory, C., Agosta, C., Delhasse, A., Doutreloup, S., Huot, P.-V., Wyard, C., Fichefet, T., and Fettweis, X.: Sensitivity of the current Antarctic surface mass balance to sea surface conditions using MAR, Cryosphere, 12, 3827-3839, 2018.

Mottram, R., Hansen, N., Kittel, C., Wessem, M. v., Agosta, C., Amory, C., Boberg, F., Berg, W. J. v. d., Fettweis, X., Gossart, A., et al.: What is the Surface Mass Balance of Antarctica? An Intercomparison of Regional Climate Model Estimates, The Cryosphere Discussions, pp. $1-42,2020$. 